DOI https://doi.org/10.46845/2541-8254-2021-3(30)-6-6

УДК 664.665

\title{
РАЗРАБОТКА РЕЦЕПТУРЫ ХЛЕБОБУЛОЧНОГО ИЗДЕЛИЯ, ОБОГАЩЕННОГО РАСТИТЕЛЬНЫМИ КОМПОНЕНТАМИ
}

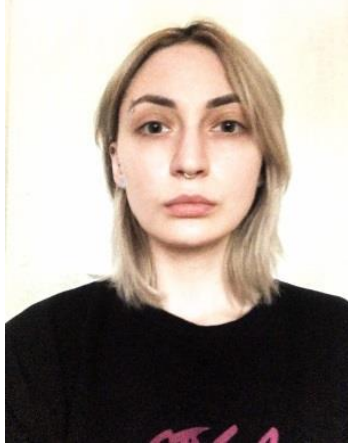

\author{
П.Д. Саватеева, магистрантка1-го курса \\ e-mail: ladyragnaryok@gmail.com \\ ФГБОУ ВО «Калининградский государственный \\ технический университет» \\ О.В Анистратова, канд. техн. наук, \\ e-mail: oksana.anistratova@klgtu.ru \\ ФГБОУ ВО «Калининградский государственный \\ технический университет»
}

Результаты проведенных маркетинговых исследований показали актуальность выбранной темы исследований по разработке рецептуры обогащенной хлебобулочной продукции среди жителей Калининградской области. Обоснован выбор растительных компонентов, используемых при проектировании хлебобулочного изделия. Изучен химический состав сухих растительных компонентов и перспективы использования в производстве хлебобулочных изделий. Проведено математическое моделирование рецептуры и получена ее математическая модель. Произведена оценка органолептических и физикохимических показателей качества хлебобулочного изделия, обогащенного растительными компонентами.

Ключевые слова: облепиховый шрот, стевиозид, цедра иүитрусовых, хлебобулочное изделие, математическое моделирование, маркетинговое исследование, кислотность, влажность мякиша, калорийность.

\section{ВВЕДЕНИЕ}

В России в 2021 г. наблюдается тенденция развития хлебопекарной промышленности. Тенденция производства хлебобулочных продуктов должна обеспечивать их максимальную доступность всем социальным и возрастным слоям населения. Использование вторичного растительного сырья, как обогащающих компонентов, в производственных масштабах встречается крайне редко. Однако применение импортного сырья очень негативно сказывается на конечной стоимости продукции. В Калининградской области имеется достаточная сырьевая база, позволяющая использовать растительное сырье в промышленных масштабах в соответствии с положениями, отраженными в нормативно-правовых актах Российской Федерации [1].

Одной из глобальных проблем, оказывающих влияние на здоровье человека и риск развития у него заболеваний, связанных с ожирением, является чрезмерное потребление сахаросодержащих продуктов. Неограниченный прием сахара может привести к преждевременному старению кровеносных сосудов, частично разрушать клеточные белки и белки крови, а также заставляет организм вырабатывать инсулинорезистентность, которая приведет к риску возникновения диабета 2-го типа. Поэтому актуальным направлением 
исследования является использование сахарозаменителя стевиозида в производстве проектируемого изделия

Одним из решений поставленных задач, наряду с применением сахарозаменителя, является обогащение продукции натуральными антиоксидантами - биофлавоноидами. Большинство биофлавоноидов термолабильны, обладают отличными противовоспалительными свойствами, а также способны укреплять стенки кровеносных сосудов.

Недостаточное потребление пищевых волокон в современном рационе населения приводит к раннему развитию проблем с желудочно-кишечным трактом. Польза пищевых волокон заключается в их способности к выведению вредных веществ и токсинов из организма. В данном случае активное и достаточное потребление продуктов, богатых пищевыми волокнами, позволяет повысить резистентность организма, особенно если речь идет о вредных условиях труда и плохой экологии [2].

\section{ОБЪЕКТ ИССЛЕДОВАНИЯ}

В качестве контрольных и опытных образцов рассматривались хлебобулочные изделия [3]. Основным компонентом при их производстве является пшеничная мука, поскольку она позволяет получить тестовые заготовки высокого качества, с хорошо сформированным клейковинным каркасом. Однако в ее составе содержится недостаточное количество пищевых волокон, биофлавоноидов.

В качестве вспомогательных компонентов для обогащения хлебобулочного изделия были выбраны: сахарозаменитель стевиозид, облепиховый шрот, цедра цитрусовых. Сахарозаменитель стевиозид получают из листьев стевии Stevia rebaudiana. Стевиозид в 300 раз слаще сахарозы, к тому же не имеет неприятного, иногда даже горького, привкуса, как многие другие сахарозаменители [4]. Облепиховый шрот - порошок обезжиренных плодов Hippophaё rhamnoides L. с кожицей и косточками. Он содержит в себе большое количество пищевых волокон, пектинов, натуральных пигментов и антиоксидантов. Цедра цитрусовых богата пищевыми волокнами, природными красителями, пектинами, флавоноидами и эфирными маслами [5]. Характеристика состава данных растительных компонентов приведена в табл. 1.

Таблица 1 - Состав сухих растительных компонентов

\begin{tabular}{|l|c|c|c|c|}
\hline $\begin{array}{c}\text { Наименование } \\
\text { показателя }\end{array}$ & $\begin{array}{c}\text { Облепиховый } \\
\text { шрот }\end{array}$ & Стевиозид & Цедра лимона & $\begin{array}{c}\text { Цедра } \\
\text { апельсина }\end{array}$ \\
\hline Белки, г & 28,7 & - & 1,5 & 0,9 \\
\hline Жиры, г & $<0,5$ & - & 0,3 & 0,1 \\
\hline Углеводы, г & 2,4 & - & 5,4 & 3,0 \\
\hline Пищевые волокна, г & 59,1 & 0,3 & 10,6 & 11,7 \\
\hline Вода, г & 4,6 & - & 82,0 & 83,7 \\
\hline Пектиновые вещества, г & 4,6 & - & 1,2 & 1,7 \\
\hline Биофлавоноиды, мг & 1200 & 12,0 & 10,0 & 14,0 \\
\hline
\end{tabular}

В качестве основы для проектирования хлебобулочного изделия была использована рецептура булочки «Дорожная», вырабатываемая по технико-технологической карте 3043 [6]. 


\section{ЦЕЛЬ И ЗАДАЧИ ИССЛЕДОВАНИЯ}

Целью настоящих исследований является разработка рецептуры хлебобулочного изделия, обогащенного растительными компонентами. Исходя из поставленной цели, были сформулированы следующие задачи исследований:

-изучение ассортиментного состава рынка хлебобулочной продукции в Калининградской области;

- анализ предпочтений потребителей при выборе хлебобулочных изделий;

- проектирование и разработка рецептуры нового хлебобулочного изделия с применением сухих растительных компонентов.

\section{МЕТОДЫ ИССЛЕДОВАНИЯ}

Маркетинговое исследование проводилось методом онлайн-анкетирования на платформе для создания анкетных форм от компании «Google». Применялся структурированный опрос, в ходе которого респонденты отвечали на одинаковые вопросы с возможностью выбора одного из вариантов ответа.

Анализ проектирования рассматриваемого продукта осуществлялся в соответствии с алгоритмом ортогонального центрального композиционного плана (ОЦКП) второго порядка для двух факторов. Подбор факторов проводился в соответствии с поставленной задачей по повышению уровня пищевых волокон и биофлавоноидов в исследуемом продукте.

Влажность готовых изделий определяли ускоренным методом на влагомере Чижова, кислотность готовых изделий - по ГОСТ 5670-68 «Хлебобулочные изделия. Метод определения кислотности». Титруемая кислотность определялась титрованием $\mathrm{NaOH} 5$ г мякиша, растертого в ступке с $50 \mathrm{~cm}^{3}$ дистиллированной воды в присутствии фенолфталеина $[9,10]$.

Расчет энергетической ценности хлебобулочных изделий проводился расчетным методом.

\section{РЕЗУЛЬТАТЫ ИССЛЕДОВАНИЯ}

В маркетинговом исследовании приняло участие 273 чел., среди которых 69,2 \% мужчин и 30,8 \% женщин в возрасте от 16 до 58 лет. Результаты анализа представлены в виде диаграмм на рис. 1-6.

Основная часть респондентов - учащиеся - 91\% (рис. 1), большинство из них (46\%) употребляет хлебобулочные изделия каждый день (рис. 2).

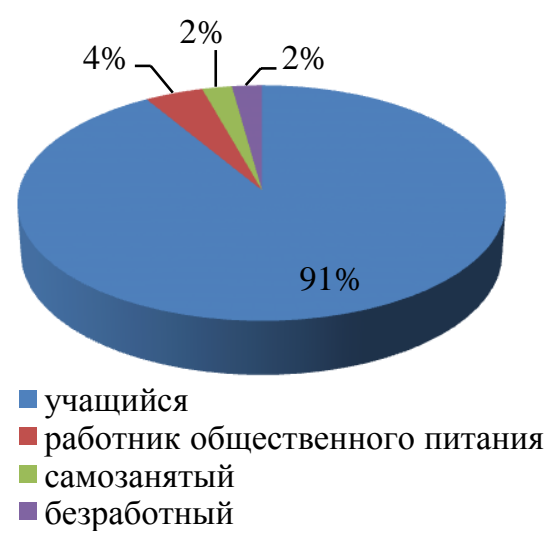

Рисунок 1 - Род занятий респондентов

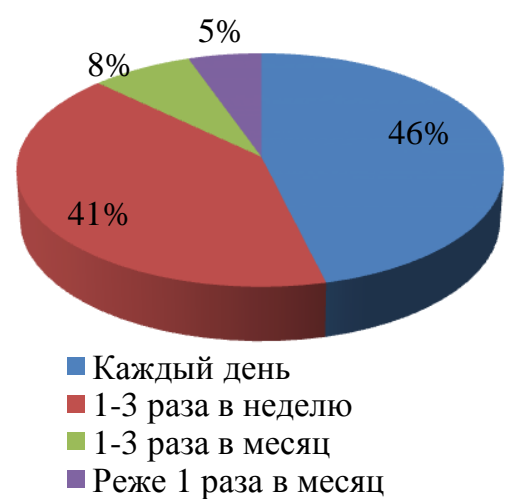

Рисунок 2 - Регулярность потребления хлебобулочных изделий 
Среди жителей Калининградской области наиболее предпочтительным является потребление хлебобулочных изделий - 58\%, также довольно популярны изделия из слоеного теста - 20\% (рис. 3). Ассортиментный состав рынка хлебобулочной продукции, по мнению $75 \%$ респондентов, недостаточно разнообразен (рис. 4).

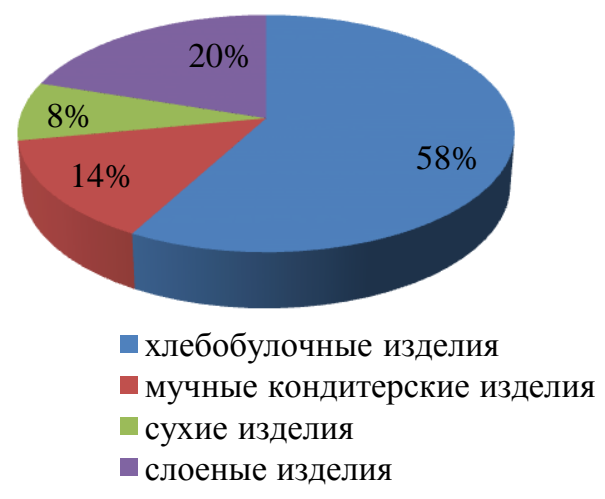

Рисунок 3 - Предпочтения при выборе вида изделия

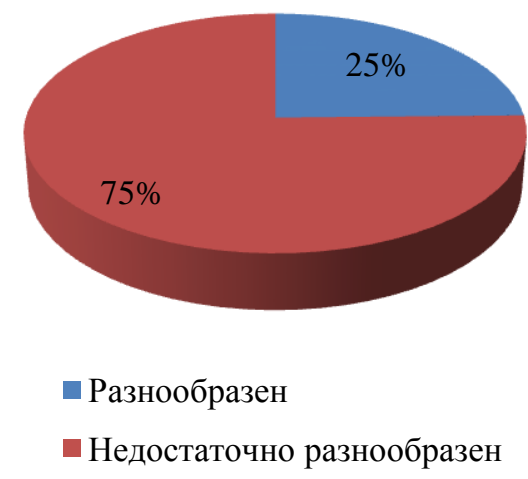

Рисунок 4 - Мнение респондентов о разнообразии ассортимента

$51 \%$ респондентов считает, что проблема качества питания населения существует и требует решения (рис. 5), 42 \% затрудняются ответить. По мнению многих опрошенных, основными группами риска в основном являются люди с хроническими заболеваниями - $27 \%$, пожилые люди - $20 \%$, беременные и кормящие женщины - $14 \%$, аллергики $-14 \%$ (рис. 6.)

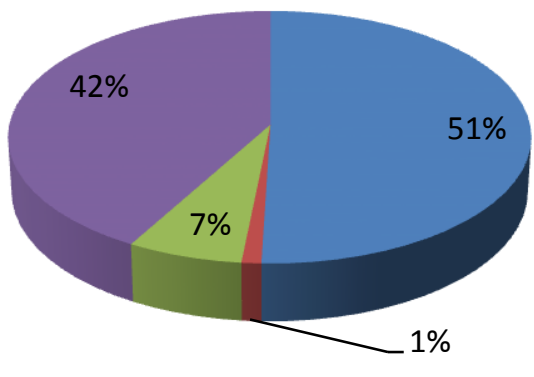

- Существует и требует решения

Рисунок 5 - Мнение респондентов о наличии проблемы качества питания

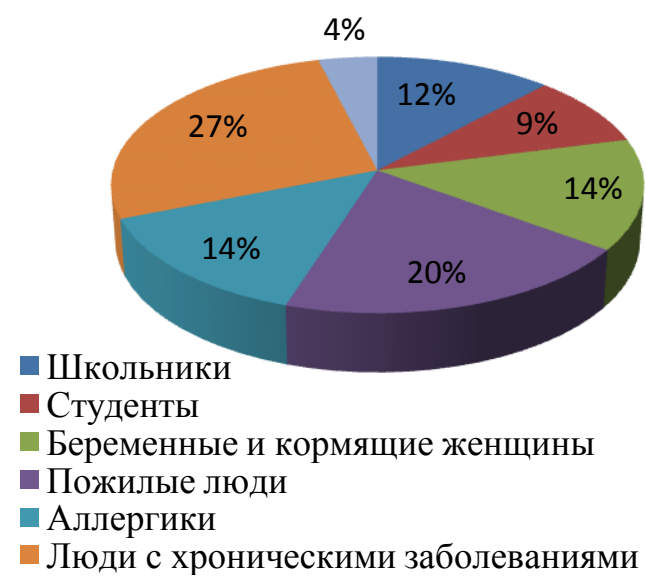

Рисунок 6 - Мнение респондентов об основных группах риска

Результаты маркетингового исследования показали, что целесообразна разработка хлебобулочных изделий с применением нетрадиционных источников сырья. Направленность проектируемого продукта будет ориентирована на людей, страдающих хроническими заболеваниями.

Планирование экспериментов при моделировании и оптимизации рецептуры обогащенной булочки осуществляли при помощи матрицы ортогонального центрального композиционного планирования второго порядка для двух факторов. 
Одним из множества факторов, влияющих на качество проектируемого хлебобулочного изделия, является количество вносимых добавок: облепихового шрота и сухого порошка стевиозида. Диапазон измерения факторов, подлежащих оптимизации $\left(\mathrm{M}_{ш}, \mathrm{M}_{\mathrm{c}}\right)$, а также пределы их варьирования приведены в табл. 2.

Таблица 2 - Изменяемые факторы, их интервалы и предельные значения

\begin{tabular}{|l|c|c|c|c|}
\hline \multirow{2}{*}{ Фактор } & \multicolumn{3}{|c|}{ Уровень } & \multirow{2}{*}{$\begin{array}{c}\text { Интервал } \\
\text { варьирования }\end{array}$} \\
\hline $\mathrm{M}_{\mathrm{m}}, \%$ & -1 & 0 & +1 & 5,0 \\
\hline $\mathrm{M}_{\mathrm{c}}, \%$ & 11,0 & 16,0 & 21,0 & 3,0 \\
\hline
\end{tabular}

Частным параметром оптимизации математической модели был выбран безразмерный обобщенный параметр оптимизации $\boldsymbol{y}$, объединяющий два частных отклика: содержание биофлавоноидов (Б, мг/100г) и содержание пищевых волокон (К, г/100 г).

При объединении частных откликов в единый обобщенный параметр оптимизации был использован метод приближения к «идеалу». Идеальные значения подобраны с учетом удовлетворения $15 \%$ от суточной нормы потребления $[7,8]$. Частные отклики и их «идеальные» значения представлены в табл. 3.

Таблица 3 - Частные отклики и их «идеальные» значения

\begin{tabular}{|l|c|c|}
\hline \multicolumn{1}{|c|}{ Наименование частного отклика } & Размерность & «Идеальное» значение \\
\hline Содержание биофлавоноидов (Б) & мг/100 г & 37,5 \\
\hline Содержание пищевых волокон (К) & г/100 г & 3,75 \\
\hline
\end{tabular}

Реализация эксперимента осуществлялась согласно матрице ОЦКП для двухфакторного эксперимента $(\mathrm{n}=2)$.

В результате вычисления коэффициентов математической регрессии получена математическая модель рецептуры в натуральном виде:

$$
\mathrm{y}=0,275+0,044 \cdot \mathrm{M}_{\mathrm{w}}-0,009 \cdot \mathrm{M}_{\mathrm{c}}-0,037 \cdot \mathrm{M}_{\mathrm{w}} \cdot \mathrm{M}_{\mathrm{c}}+0,217 \cdot\left(\mathrm{M}_{\mathrm{w}}^{2} \cdot \frac{2}{3}\right)+0,111 \cdot\left(\mathrm{M}_{\mathrm{c}}^{2} \cdot \frac{2}{3}\right)
$$

При решении математической регрессии были получены оптимальные количественные значения заданных факторов: массовая доля вносимого облепихового шрота к массе муки составила 11,47 \%, а массовая доля сухого порошка стевиозида к массе муки $4,12 \%$.

Графическая интерпретация модели представлена на рис. 7. 


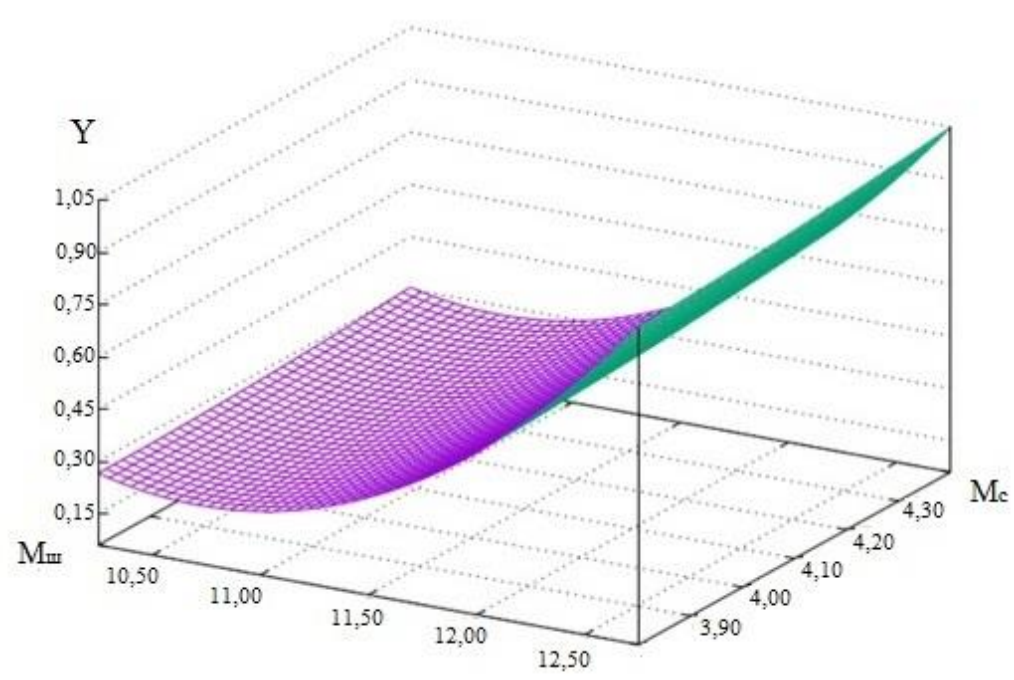

Рисунок 7 - Графическая интерпретация математической модели

Для придания изделию приятного вкусу и аромата было решено использовать цедру цитрусовых в количестве не более $2 \%$ от количества муки. Применение цедры цитрусовых позволяет дополнительно обогатить изделие пищевыми волокнами и эфирными маслами, оказывающими благоприятное влияние на желудочно-кишечный тракт. Использование более 2 \% цедры цитрусовых придает изделию выраженный горький вкус (табл. 4).

Таблица 4 - Рецептура хлебобулочного изделия, обогащенного растительными компонентами на 100 изделий массой 50 г

\begin{tabular}{|l|c|c|}
\hline \multirow{2}{*}{ Наименование ингредиента, кг } & \multicolumn{2}{|c|}{ Исследуемые образцы } \\
\cline { 2 - 3 } & Контроль & Опыт \\
\hline Мука пшеничная хлебопекарная высший сорт & 37,0 & 32,9 \\
\hline Мука пшеничная (на подпыл) & 1,2 & 1,2 \\
\hline Сахар & 7,0 & - \\
\hline Шрот облепиховый (порошок) & - & 4,0 \\
\hline Цедра лимона & - & 0,66 \\
\hline Цедра апельсина & - & 0,66 \\
\hline Стевиозид (порошок) & - & 1,5 \\
\hline Масло сливочное & 8,0 & 8,0 \\
\hline Масло сливочное (для смазки) & 1,2 & 1,2 \\
\hline Соль & 0,4 & 0,4 \\
\hline Дрожжи прессованные & 0,9 & 0,9 \\
\hline Молоко коровье натуральное & 18,5 & 18,5 \\
\hline Итого сырья & 74,2 & 71,0 \\
\hline
\end{tabular}

Готовые изделия производились в соответствии с рецептурами (табл. 5), хлебобулочные - выпекались в пароконвектомате при температуре $180 \pm 5^{\circ} \mathrm{C}$ в течение 12 мин.

Готовые хлебобулочные изделия оценивались по органолептическим и физикохимическим показателям (рис. 8, 9, табл. 5) 


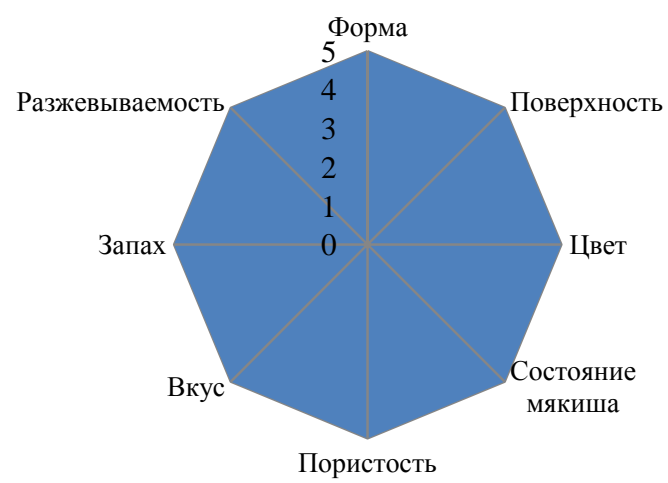

Рисунок 8 - Органолептическая оценка показателей контрольного образца

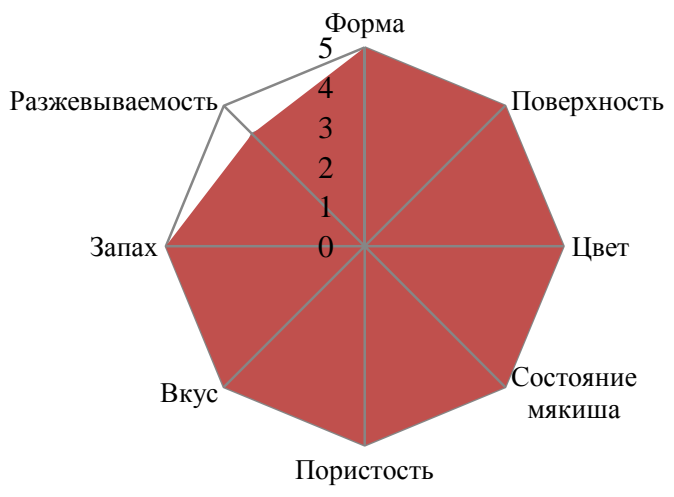

Рисунок 9 - Органолептическая оценка показателей опытного образца

Для подтверждения соответствия физико-химических показателей спроектированного изделия требованиям нормативной документации был проведен сравнительный анализ влажности мякиша и титруемой кислотности готовых изделий (табл. 6).

Таблица 5 - Физико-химические показатели готовых изделий

\begin{tabular}{|c|c|c|c|}
\hline \multirow{2}{*}{ Наименование показателя } & \multirow{2}{*}{$\begin{array}{c}\text { Нормативное } \\
\text { значение, } \\
\text { не более }\end{array}$} & \multicolumn{2}{|c|}{ Образец } \\
\hline & & Контрольный & Опытный \\
\hline Влажность мякиша, \% & $34,00 \pm 0,50$ & $27,98 \pm 0,50$ & $32,72 \pm 0,50$ \\
\hline Титруемая кислотность, град & $2,5 \pm 0,50$ & $2,4 \pm 0,50$ & $2,1 \pm 0,50$ \\
\hline
\end{tabular}

Для того чтобы определить энергетическую ценность проектируемого изделия, был исследован химический состав образцов хлебобулочной продукции. Общий химический состав изделий представлен в табл. 6.

Таблица 6 - Общий химический состав изделий, г/100 г продукта

\begin{tabular}{|l|c|c|c|c|c|}
\hline \multicolumn{1}{|c|}{ Образец } & Белки, г & Жиры, г & Углеводы, г & $\begin{array}{c}\text { Пищевые } \\
\text { волокна, } \Gamma\end{array}$ & $\begin{array}{c}\text { Биофлавоноиды, } \\
\text { мг }\end{array}$ \\
\hline Контрольный & $7,9 \pm 1,6$ & $9,4 \pm 2,0$ & $55,5 \pm 3,1$ & $0,6 \pm 0,1$ & $5,6 \pm 0,8$ \\
\hline Опытный & $8,2 \pm 1,8$ & $9,0 \pm 2,0$ & $44,7 \pm 2,4$ & $6,9 \pm 4,2$ & $38,2 \pm 1,6$ \\
\hline
\end{tabular}

По результатам проведенных исследований энергетическая ценность контрольного образца составила 338,2 ккал, опытного образца (без учета абсолютной погрешности) 292,6 ккал.

Результаты расчетов показали, что энергетическая ценность продукта понизилась на $13,5 \%$; количество белка увеличилось на 3,8 ; количество жиров уменьшилось на 4,3; количество углеводов уменьшилось на 19,5 \%. Существенно увеличился уровень биофла- 
воноидов и пищевых волокон за счет обогащающих компонентов - на 582,1 и 1050,0 \% соответственно [11, 12].

\section{ЗАКЛЮЧЕНИЕ}

По результатам маркетингового исследования было определено, что хлебобулочные изделия являются продуктом ежедневного массового потребления. При проектировании их рецептуры целесообразной является разработка изделия с применением сухих растительных компонентов: облепихового шрота, стевиозида, цедры цитрусовых.

Было проведено математическое моделирование рецептуры булочки «Дорожная» с целью определения оптимальных дозировок для облепихового шрота и стевиозида. Проектируемое изделие должно удовлетворять суточную норму потребления пищевых волокон и биофлавоноидов. По результатам математического моделирования были получены уравнение регрессии в натуральном виде и графическая интерпретация модели, подчеркивающая адекватность ее применения. Принято решение внести в рецептуру дополнительные ароматические добавки - цедру лимона и апельсина в количестве не более 2 \% от содержания муки. Цедра цитрусовых позволит подчеркнуть органолептические достоинства проектируемого изделия, а также будет являться дополнительным источником пищевых волокон.

Производилось сравнительное исследование физико-химических показателей изделия с целью подтверждения качества проектируемого изделия. Влажность мякиша и титруемая кислотность в опытном образце не превышали значения, трактуемые в нормативной документации.

Для обоснования группы профилактического продукта провели анализ энергетической ценности образцов. Опытный образец является продуктом пониженной калорийности.

По результатам исследований доказано, что применение сухих растительных компонентов при производстве хлебобулочных изделий позволяет получить качественный продукт, отвечающий требованиям нормативной документации. Проектируемое изделие рекомендуется к употреблению лицам с хроническими заболеваниями, а также для профилактики появления лишнего веса, болезней желудочно-кишечного тракта и сердечнососудистой системы.

\section{СПИСОК ЛИТЕРАТУРЫ}

1. Косован, А.П. Программа развития хлебопекарной промышленности до 2020 г. / А.П. Косован, И.И. Шапошников // Хлебопечение России. - 2011. - № 4. - С. 4.

2. Кольман, О.Я. Вторичные сырьевые ресурсы как биологически активная добавка направленного действия / О.Я. Кольман, Г.В. Иванова // Здоровье населения и среда обитания. - 2012. - № 7. - С. 30-32.

3. ГОСТ 32677-2014 Изделия хлебобулочные. Термины и определения. [Электронный pecypc] - https://docs.cntd.ru/document/1200113580 Дата обращения: 02.05.2021

4. Свойства и возможности использования в питании натурального подсластителя - стевиозида / Ж.Ю. Горелова [и др.] // Педиатрическая фармакология. - 2005. № 5. 
5. Отходы цитрусовых - биологически ценные компоненты для пищевых продуктов и напитков / Е.И. Курбатова [и др.] // Пиво и напитки. - 2013. - № 5.

6. Технико-технологическая карта 3043 Булочка «Дорожная» (ТТК3043) [Электронный ресурс] - https://tekhnolog.com/2018/09/06/bulochka-dorozhnaya-ttk3043/ Дата обращения: 02.05.2021

7. Методические рекомендации МР 2.3.1.2432-08 «Нормы физиологических потребностей в энергии и пищевых веществах для Различных групп населения Российской Федерации». - Москва, 2008.

8. Мезенова, О.Я. Проектирование комбинированных продуктов питания: учеб. пособие / О. Я. Мезенова. - Калининград: ФГБОУ ВПО «КГТУ», 2012. - 172 с.

9. Корячкина, С.Я. Методы исследования свойств сырья, полуфабрикатов и готовой продукции. Методы исследования свойств растительного сырья: учебнометодическое пособие для высшего профессионального образования / С.Я. Корячкина, Н.А. Березина, Е.В. Хмелева. - Орел: ФГОУ ВПО «Госуниверситет-УНПК», 2011. - 300 с.

10. ГОСТ 27844-88 «Изделия булочные. Технические условия». - Москва: Госстандарт, 1990. - 9 с.

11. ГОСТ 33999-2016 Продукция пищевая специализированная. Продукция пищевая диетического лечебного и диетического профилактического питания. Термины и определения - [Электронный ресурс] - https://docs.cntd.ru/document/1200145604 Дата обращения: 02.05.2021

12. ГОСТ Р 51074-2003 «Продукты пищевые. Информация для потребителя. Общие требования». - Москва: Госстандарт, 2003-14 с.

\title{
DEVELOPMENT OF A BAKERY RECIPE PRODUCTS ENRICHED DRY PLANT COMPONENTS
}

\author{
P.D. Savateeva, 1st year master's degree student \\ e-mail: ladyragnaryok@gmail.com \\ Kaliningrad State Technical University \\ O.V. Anistratova, $\mathrm{PhD}$, Associate Professor \\ e-mail: oksana.anistratova@klgtu.ru \\ Kaliningrad State Technical University
}

The results of the conducted marketing research showed the relevance of the chosen research topic for the development of the recipe for enriched bakery products among the residents of the Kaliningrad region. The choice of plant components used in the design of a bakery product is justified. The chemical composition of dry plant components and the prospects for use in the production of bakery products are studied. Mathematical modeling of the recipe is carried out and its mathematical model is obtained. The assessment of organoleptic and physico-chemical indicators of the quality of bakery products enriched with plant components was carried out.

Key words: sea buckthorn meal, stevioside, citrus zest, bakery product, mathematical modeling, marketing research, acidity, crumb moisture, calorie content 